\title{
イオンビームスパッタ法による $\mathrm{CoSb}_{3}$ 薄膜の 作製と熱電特性*1
}

\author{
山下裕 $-1, * 2 \quad$ 松井利之 $2^{2}$ 森井賢 二² \\ ${ }^{1}$ 大阪府立大学大学院工学研究科 \\ 2大阪府立大学工学部
}

J. Japan Inst. Metais, Vol. 64, No. 5 (2000), pp. 351-354

Papers from JIM Fall Meeting (1999)

(C) 2000 The Japan Institute of Metals

\section{Thermoelectric Properties of $\mathrm{CoSb}_{3}$ Thin Films Prepared by Ion-Beam Sputtering}

\author{
Yuichi Yamashita ${ }^{1, * 2}$, Toshiyuki Matsui ${ }^{2}$ and Kenji Morii ${ }^{2}$ \\ ${ }^{1}$ Department of Metallurgy and Materials Science, College of Engineering, Osaka Prefecture University, \\ Sakai 599-8531 \\ ${ }^{2}$ College of Engineering, Osaka Prefecture University, Sakai 599-8531
}

\begin{abstract}
In order to synthesize thin films of a $\mathrm{CoSb}_{3}$ compound, thin $\mathrm{Co} / \mathrm{Sb}$ multi-layered films were prepared by an ion-beam sputtering method, and annealed in a temperature range between 673 and $773 \mathrm{~K}$ for 1 to $3 \mathrm{~h}$ in a vacuum atmosphere. The effects of both chemical composition and annealing conditions on the $\mathrm{CoSb}_{3}$ phase evolution were evaluated by $\mathrm{X}$-ray diffraction and transmission electron microscopy. The thermoelectric properties of the annealed films were studied at elevated temperatures. The results obtained are summarized as follows: In a rather wide composition range such as 70 to $85 \mathrm{at} \% \mathrm{Sb}$, thin films consisting of a $\mathrm{CoSb}_{3}$ single phase were successively synthesized. The $\mathrm{CoSb}_{3}$ films showed a p-type semiconducting character, and their thermoelectric transport properties were found to be nearly closed to those of bulk materials reported so far. It was also found that the grain size, electrical conductivity and Seebeck coefficient of the $\mathrm{CoSb}_{3}$ films were dependent on their chemical composition after annealing.
\end{abstract}

(Received December 20, 1999; In Final Form, February 22, 2000)

Keywords: thermoelectric material, skutteldite compound $\mathrm{CoSb}_{3}$, thin film thermoelectrics, multi-layered film, solidstate reaction, thermoelectric properties

\section{1. 緒言}

電子デバイスの高性能化，高集積化に伴い動作中に発生す る熱の制御が重要な課題の一つとなっている11. 薄膜熱電变 換材料はデバイスレベルでの熱管理を可能にする材料として その開発が期待されている2,3).

$\mathrm{CoSb}_{3}$ はスクッテルダイト構造 $\left(\mathrm{CoAs}_{3}\right.$ 型, $\mathrm{Im} 3, a=$ $0.9039 \mathrm{~nm})$ を持つ化合物で，狭いバンドギャップと高い正 孔移動度を特徵とする $\mathrm{p}$ 型半導体である ${ }^{4,5)}$. 単位格子は 8 つのCoサブ格子よりなり，その内の6つが $\mathrm{Sb}$ リングを含 み，残り2つは空となっている。このような構造上の特徽 のためK, $\mathrm{CoSb}_{3}$ 化合物は例党ば不純物のドーピングある いは空の Co サブ格子への第 3 元素添加などにより大きな電 子構造の変化，したがって熱電気的特性の改善が期待され， 新しい熱電変換材料としての可能性を秘めていると考光られ ている6)。このため, $\mathrm{CoSb}_{3}$ に関して活発な研究が進められ ているが，これらの多くはバルク材に関するものが主 で4,5,7,8)，例之ば電子デバイスへの応用を想定した $\mathrm{CoSb}_{3}$ 薄 膜汇関寸る研究報告は少ないのが現状である,10)。

本研究では以上のよ5な観点から $\mathrm{CoSb}_{3}$ 化合物をとりあ

\footnotetext{
*1 1999年11月22日日本金属学会秋期大会に特いて発表

*2 大阪府立大学大学院生 (Graduate Student, Osaka Prefecture University)
}

げ，その薄膜化を検討することにした。これまでに， $\mathrm{CoSb}_{3}$ 焼結体をターダットとしたrf-マグネトロン・スパッタ法9), レーザー・アブレション法10)に上る $\mathrm{CoSb}_{3}$ 薄膜作製の報告 があるが，いずれる構成元素の蒸気圧が大きく異なるために 薄膜の組成制御に大きな課題が残るとされている. 本研究で は薄膜化の方法としてイオンビーム・スパッタ(IBS)法と固 相反応法を組合せた。この手法は多層膜の作製と固相反応に よる相形成を分離することができ，薄膜組成の制御が容易で あるといら利点を有する11)。なお，真空蒸着 $\mathrm{Y} / \mathrm{Fe} / \mathrm{Sb}$ 多層 膜の熱処理によって準安定 $\mathrm{YFe}_{4} \mathrm{Sb}_{12}$ 相を合成した例も報告 されている12)。このように多首膜の固相反応法は微量元素 の添加や準安定相の形成に対しても有効な手法である.

\section{2. 実 験 方 法}

本実験では $\mathrm{CoSb}_{3}$ 相を $\mathrm{Co} / \mathrm{Sb}$ 多層膜の固相反応によって 合成する方法を検討する，多層膜は Ar ガスを動作がスとす るIBS 法により作製した。ダーゲットルは99.997\%の Co 板


以下の真空度に排気後, $\mathrm{Ar}$ ガス星を $8 \times 10^{-2} \mathrm{~Pa}$ とし, 放電 電生/電流を $7 \mathrm{kV} / 7 \mathrm{~mA}$ の条件でスパッ夕を行った。基板に はガラス(Corning \#7059)を用い，基板温度は室温とした。 なお，ガラス基板はアセトンによる超音波洗浄後，成膜室で 脱ガス处理を行らとともに，ターゲット表面をプレスパッタ 


\section{により清浄化した.}

多層膜は $\mathrm{Co}$ と $\mathrm{Sb}$ それぞれ所定時間の間スパッタする ことにより作製した. $\mathrm{Co} / \mathrm{Sb}$ 層の周期を $8 \mathrm{~nm}$ とし，これを 30 回積厤し，総膜厚を $240 \mathrm{~nm}$ とした. Fig. 1 Kとの模式図 を示す．多層膜の平均組成仙 $\mathrm{Co} / \mathrm{Sb}$ 層の相対厚さを変化さ せることにより調整した。本研究では， $\mathrm{CoSb}_{3}$ 相の合成を 目的としているので, この相の化学量諭組成 $(\mathrm{Co}: \mathrm{Sb}=1$ : 3)を中心に，数種類の組成の多層膜を設計した.

作製した多層膜に真空炉中で $673 \sim 773 \mathrm{~K}$ の温度範囲で， 1 3 h の熱処理を加光 $\mathrm{Co} / \mathrm{Sb}$ 層の固相反㐫を進めた．固相 反応に伴う相形成の経過を X 線回折 $(\mathrm{CuK} \alpha$ 線)により調心゙ ると同時に，膜のミクロ組織を透過電子顕徽鏡 (TEM)Kよ り観察した。 TEM 用試料は膜面平行にイオンミリングによ り作製した。すた熱処理前後の薄膜の平均組成をX 線マイ クロアナライザー(EPMA)炕より分析した.

固相反心後の薄膜について，4探針法に上る直流伝導度拉 よび熱起電力の湘定を行った。な拉，㵋定は真空中で，室温 $\sim 573 \mathrm{~K}$ の温度䉓聿とした。試料江气た温度差 $\Delta T(2 \sim 5$ K)牧よび測定された熱起電力 $\Delta V$ より，ゼーベック係数 $\alpha$ $=\Delta V / \Delta T$ 求めた。

\section{3. 実験結果および考察}

\section{1 固相反店に伴う相形成}

まず，作製された $\mathrm{Co} / \mathrm{Sb}$ 組成の異なる多層膜について， 膜組成と多層膜構造について検討した。いずれの試料に招い て子，注活設計組成に近い $\mathrm{Co} / \mathrm{Sb}$ 組成を持つ多層膜が作製 された．実験に用いた試料の名称，熱処理前後のEPMA 分 析の結果を Table 1 K示寸. 多層膜試料の低角度域での X 線回折パターンには0次ピークのサテライトとして3〜4次 のピークが認められ，周期性のよい $\mathrm{Co} / \mathrm{Sb}$ 層の積層が形成 されている。しかし高角度域のパターンには鋭いピークは観 察できず，多層膜を構成するCo叔よび Sb 層はつモルフ スかもしくは微細粒組織であると推測できる。

次に，これらの試料に固相反応を起こすために $673 \sim 773$ $\mathrm{K}, 1 \sim 3 \mathrm{~h}$ の熱观理を加衣, 膜組成の変化亡相形成挙動を調 べた. 熱処理後の膜組成は全体的に $\mathrm{Sb}$ 量が減少する傾问が

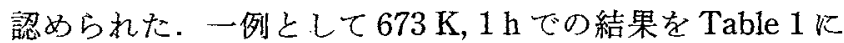

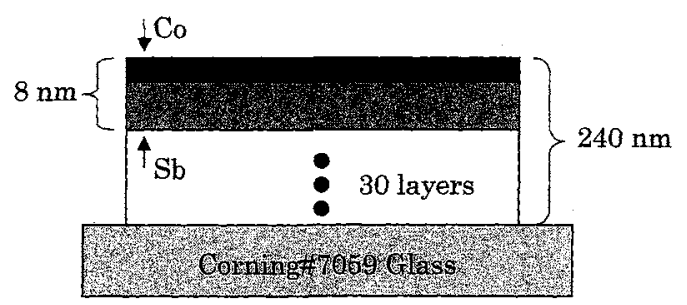

Fig. 1 Schematic illustration of the multi-layered thin film of cobalt and antimony.

Table 1 Compositions (atom.\%) for as sputtered and annealed $\mathrm{Co}-\mathrm{Sb}$ samples measured by EPMA.

\begin{tabular}{ccc}
\hline \multirow{2}{*}{ Samples } & \multicolumn{2}{c}{ Compositions (Co/Sb ratio) } \\
\cline { 2 - 3 } & As sputtered & Annealed $(673 \mathrm{~K}, 1 \mathrm{~h})$ \\
\hline No. 1 & $1: 6.14$ & $1: 3.27$ \\
\hline No. 2 & $1: 3.46$ & $1: 3.15$ \\
\hline No. 3 & $1: 3.39$ & $1: 3.12$ \\
\hline No. 4 & $1: 2.55$ & $1: 2.51$ \\
\hline No. 5 & $1: 2.09$ & $1: 1.96$ \\
\hline
\end{tabular}

示す。この傾向は高温，長時間の熱処理で，Sbリッチの試 料に特いて顕著であったことから, 固相反応の過程で $\mathrm{Sb}$ 膜から離脱(昇華)することに起因すると考光られる。この点 からは，低温，短時間の熱処理ほど好ましいといえる。な お。，No. 2 および No. 3 の試料では熱処理によって $\mathrm{CoSb}_{3}$ の 化学量論組成に近い薄膜が得られていることがわかる.

Table 1 にあげた試料に対して $673 \mathrm{~K}, 1 \mathrm{~h}$ の条件で固相反 応させた後のX線回折パターンをFig. 2 に示す.な执参考 のために $\mathrm{CoSb}_{3}$ 相と $\mathrm{CoSb}_{2}$ 相の計算回折強度を加光た。こ の図より No. 5 試料を除けば 70 85 at\% Sb 範囲でほとん ど配向性を持たない $\mathrm{CoSb}_{3}$ 単相膜が形成されていることが わかる.X線回折パターンから概算される $\mathrm{CoSb}_{3}$ の格子定 数は $0.9034 \mathrm{~nm}$ でバルク結晶に扣いて報告されている值 $(0.9039 \mathrm{~nm})^{4)}$ とほぼ等しいことがわかった. No. 5 試料に は $\mathrm{CoSb}_{2}$ 相の形成が見られるが，こ礼は熱処理前の膜組成 が $\mathrm{Co}: \mathrm{Sb}=1: 2.09$ となって和り， $\mathrm{CoSb}_{2}$ 相の量論組成に ほ注等しいことによると考觉られる。をた，熱㛆理前の膜組 成が 75 at \% Sb 以上の試料では，例克ばNo. 1 試料のように $\mathrm{CoSb}_{3}$ の量論組成からかなり外れていても熱超理後には化 学量論組成火近い値となっている，このことは， $\mathrm{CoSb}_{3}$ の 形成に伴って余分の Sb が固相反応中に離脱することを意味 している.

その他の条件で熱処理した試料炕いても上と同様の相形 成挙動が認められたが, 高温, 長時間の熱処理ほど, Sbの 離脱に伴ら膜表面の劣化が観察された。 このため以下の観 察, 湘定には $673 \mathrm{~K}, 1 \mathrm{~h}$ の熱処理を施した試料を用いた.

次火, 固相反応 $(673 \mathrm{~K}, 1 \mathrm{~h})$ 後の試料のミク口組織を TEM 観察した。 その結果を Fig. 3 に示す.いずれの試料に


が，平均粒径は荧組成に依存する傾向にある. $\mathrm{CoSb}_{3}$ の化 学量論組成に近いNo. 2 和よび No. 3 の試料では 100 200 $\mathrm{nm}$, Co リッチの組成の No. 4 試料では $80 \sim 100 \mathrm{~nm}$ と見積

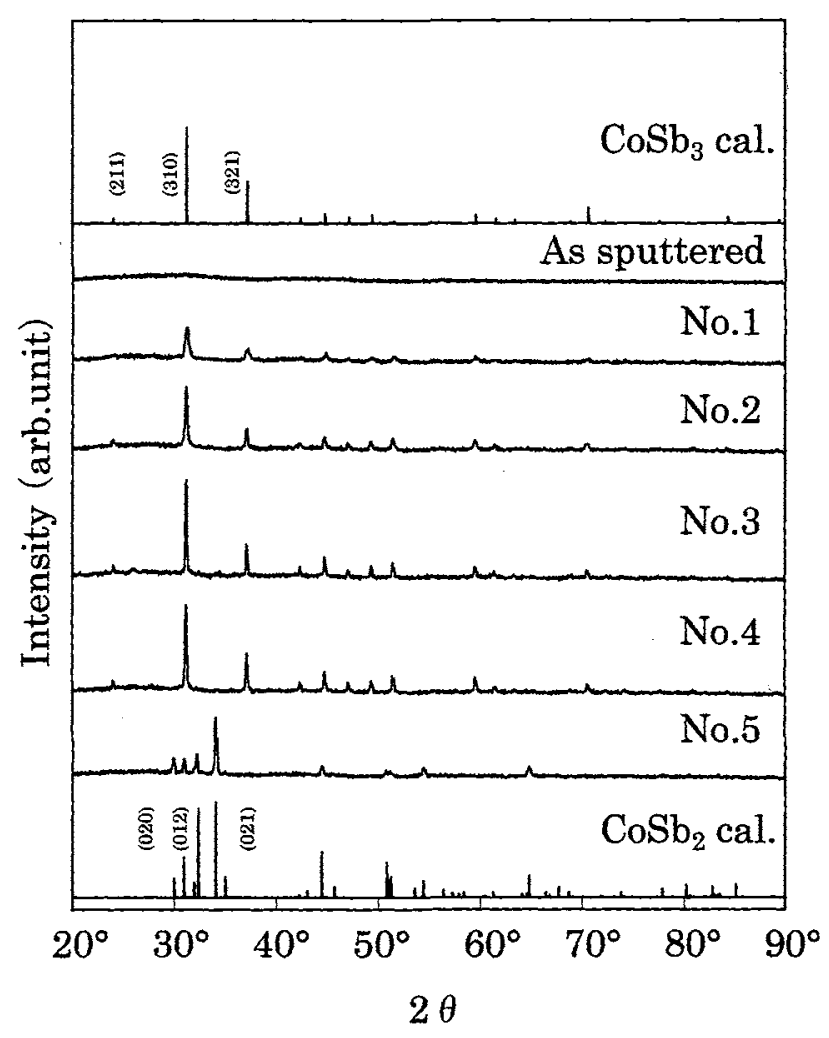

Fig. 2 X-Ray diffraction patterns of the samples annealed at $673 \mathrm{~K}$ for $1 \mathrm{~h}$. 

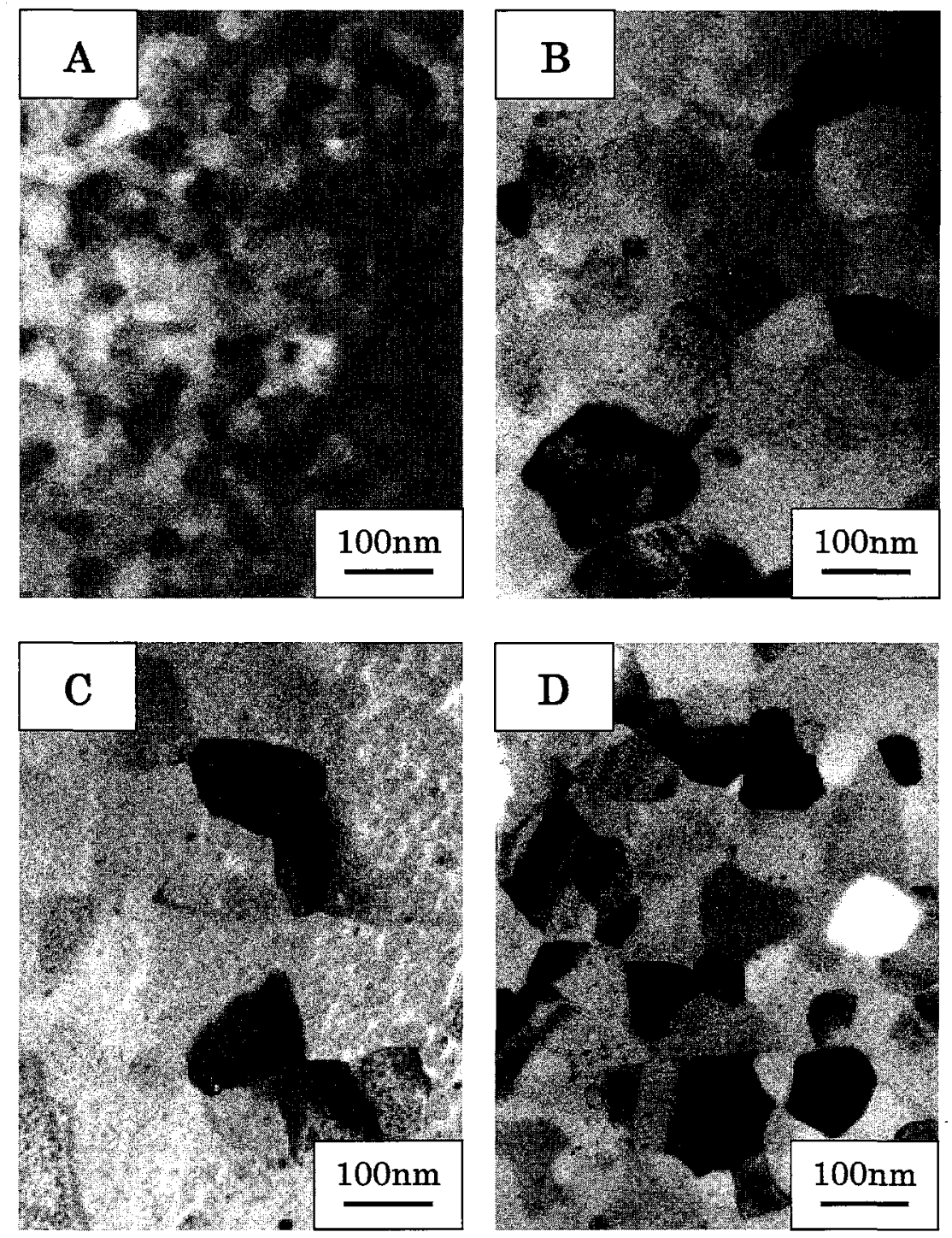

Fig. 3 TEM micrographs of the samples annealed at $673 \mathrm{~K}$ for $1 \mathrm{~h}$.

A: sample No. 1, B: sample No. 2, C: sample No. 3, and D: sample No. 4.

あられる。これに対しSbリッチのNo. 1 試料では 30〜40 $\mathrm{nm}$ とかなり微細な粒径であった。な拝，回折パターンはい ずれも $\mathrm{CoSb}_{3}$ 相からのリングにより指数つけけでさるもので あった。したがって，これらの試料に执いてはミク口的にも 注卧 $\mathrm{CoSb}_{3}$ 単相膜が形成されていると考古られるが，

Table 1 に示した熱処理後の試料についての組成分析結果を 考慮すると，微量の未反応 SbむるいはCoないしこれらの 酸化物が存在している可能珄もある. No. 1 扣よび No. 4 試 料では熱処理前の組成が化学量論組成からかなりずれている ためにこれら微細第2 相を含んでいる可能性があり，この ため粒成長が抑制され比較的小さな結晶粒になったと推測さ れる.さらに，No.1 試料については熱処理中の Sbの離脱 により著しい膜厚の减少が認められたので, 次のよらな可能 性も指摘でさる。すなわち，多層膜に特惊る膜厚減少は単位 体積あたりの層界面の比率を増加し，層界面はさらに化合物 結晶の優先的核形成の場を与えるので, 結果として膜厚の減 少が微細粒の形成につながったと考えることができる。

本研究の固相反応で得られた $\mathrm{CoSb}_{3}$ 薄膜 (No. 2, No. 3) 性 上述のよらに泳湆化学量論組成で，汪とんど配向性をもた ず，季た薄膜の結晶粒径は喥結法や溶融法で作製されるバル ク材のそれに比較して1桁あるいはそれ以上小さい7)とい。 た特徴を有している。

\section{$3.2 \mathrm{CoSb}_{3}$ 薄膜の熱電気的特性}

固相反応 $(673 \mathrm{~K}, 1 \mathrm{~h})$ により底济 $\mathrm{CoSb}_{3}$ 単相膜が得られた 試料(No. 1〜No. 4) そついて, 電気的特性を調べた. Fig. 4 にこれら試料の直流伝望度 $\boldsymbol{\sigma}$ の温度依存性を示す。いずれ の試料に执いても, 室温以上の温度域で盜度とともにゆるや

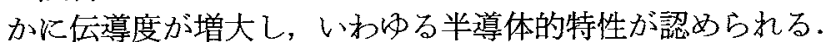
$500 \mathrm{~K}$ を超觉る領域では后導度の增大がわずかに大きくな がそれ以下の領域では $\log \sigma$ と1/Tのプロットは汪湆線に 近似できる。伝導度次式 $\sigma=\sigma_{0} \exp \left(-E_{\text {cond }} / k_{\mathrm{B}} T\right)$ にフ \%卜さ好て求められた電気伝導の活性化エネルギー $\left(E_{\text {cond }}\right)$ は No. 2, No. $3: 18 \mathrm{meV}$, No. $4: 16 \mathrm{meV}$, No. $1: 6 \mathrm{meV}$ と 見積もら礼た。な抗上式で $\sigma_{0}$ は定数， $k_{\mathrm{B}}$ はボルッマン定 数，Tは温度である. 活性化エネルギーの 2 倍をこの領域 での不純物準位 $\left(E_{\mathrm{A}}\right)$ と仮定すると本研究での $\mathrm{CoSb}_{3}$ 薄膜の $E_{\mathrm{A}}$ は $12 \sim 36 \mathrm{meV}$ 程度の値となる. $\mathrm{CoSb}_{3}$ 結晶関する最 近のバンド計算13)ではェネルギーギャップ $E_{\mathrm{g}}$ が $0.22 \mathrm{eV}$ と 推定されていることを考慮すると，ギャップ内に不純物ある いは欠陥などによる準位が生じている可能性がある。しか 乙， $E_{\mathrm{g}}$ を $50 \mathrm{meV}$ と推定するバンド計算結果も報告 ${ }^{14)}$ され ているので現状では断定できない。また，Fig. 4 は伝導度の 值が試料の組成によってかなり変化することを示している。 No. 1 扣よびNo. 4 試料がやや低い伝導度を示すのは，前節 


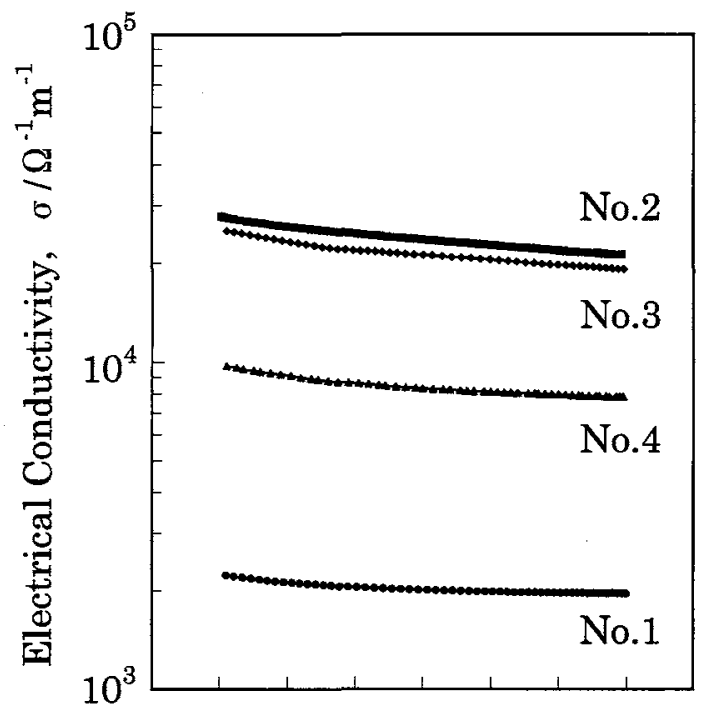

$\begin{array}{lllllllll}1.6 & 1.8 & 2 & 2.2 & 2.4 & 2.6 & 2.8 & 3 & 3.2\end{array}$

Temperature, $T^{-1} / 10^{-3} \mathrm{~K}^{-1}$

Fig. 4 Temperature dependence of dc conductivity of the samples annealed at $673 \mathrm{~K}$ for $1 \mathrm{~h}$.

で述べたよらに，熱処理前の多層膜組成が $\mathrm{CoSb}_{3}$ の化学量 論組成からずれていることによって生ずる微量第 2 相の形 成ないし粒径の減少に関俰寸ると考えることができる。な 和, 得られた $\mathrm{CoSb}_{3}$ 薄膜の電気伝導度は $\mathrm{CoSb}_{3}$ 焼結体につ いて報告されている值7,8)と注涪同程度である。

次注，これら試料のゼーベック係数 $\alpha$ の温度依存性を Fig. 5 К示す. $\alpha$ の符号はいずれの試料についても正であ り, 本研究の $\mathrm{CoSb}_{3}$ 薄膜が $\mathrm{p}$ 型の半導体であることを示し ている. 300 $600 \mathrm{~K}$ の温度範囲で $\alpha$ は汪洼直線的に増大 し, No. 2 試料では $573 \mathrm{~K} て ゙ 120 \mu \mathrm{V} / \mathrm{K}$ の值を示した。 た，各試料の $\alpha$ には上述の伝導度の場合之同様の膜組成依 存性が認められ，微量第 2 相ないし結晶粒径とゼーベック 係数との相関が推測される。な和，バルク $\mathrm{CoSb}_{3}$ 結晶に和 いても， $\alpha$ は温度の上昇に伴って増大寸る傾向が認められ， $200 \mu \mathrm{V} / \mathrm{K}$ 程度の值に達することが報告されている4,6,8). 本 研究での $\mathrm{CoSb}_{3}$ 薄膜の $\alpha$ はそれに比較すれば全体的に若干 小さな值となっている，上の議論から推測すると，これは実 験で得られた $\mathrm{CoSb}_{3}$ 薄膜では一般的なバルク材に比較して 結晶粒径が 1 桁以上も小さい7)ことや微量不純物量が異なる ことなどに関係していると考学られる。しかし，結論はぜ一 ベック係数と直接的に関係するキャりア濃度, 移動度峈るい は有効質量等の測定を通した検討を待たねばならない。

以上のよらに, 固相反応によって得られた $\mathrm{CoSb}_{3}$ 薄膜も 焼結法などで作製されたバルク材とほ淁同程度の熱電気特性 を示导ことがわかった。

\section{4. 結言}

スクッテルダイト型 $\mathrm{CoSb}_{3}$ 化合物の薄膜化を目的として, IBS 法により作製した $\mathrm{Co} / \mathrm{Sb}$ 多層膜の固層反応を検討し, 得られた薄膜の熱電気特性を評価した。主な結果をまとめる と以下のようになる。

（1）積層周期 $8 \mathrm{~nm}, \mathrm{Co} / \mathrm{Sb}$ 組成比 $1 / 4$ ，積層回数 30 とした $\mathrm{Co} / \mathrm{Sb}$ 多層膜に真空炬中で $673 \mathrm{~K}, 1 \mathrm{~h}$ の熱処理を加えるこ とにより，活济化学量論的組成をbつ $\mathrm{CoSb}_{3}$ 単相薄膜を合 成することができた。そのミク口組織は平均粒径 100１20 $\mathrm{nm}$ の等軸組織であった。

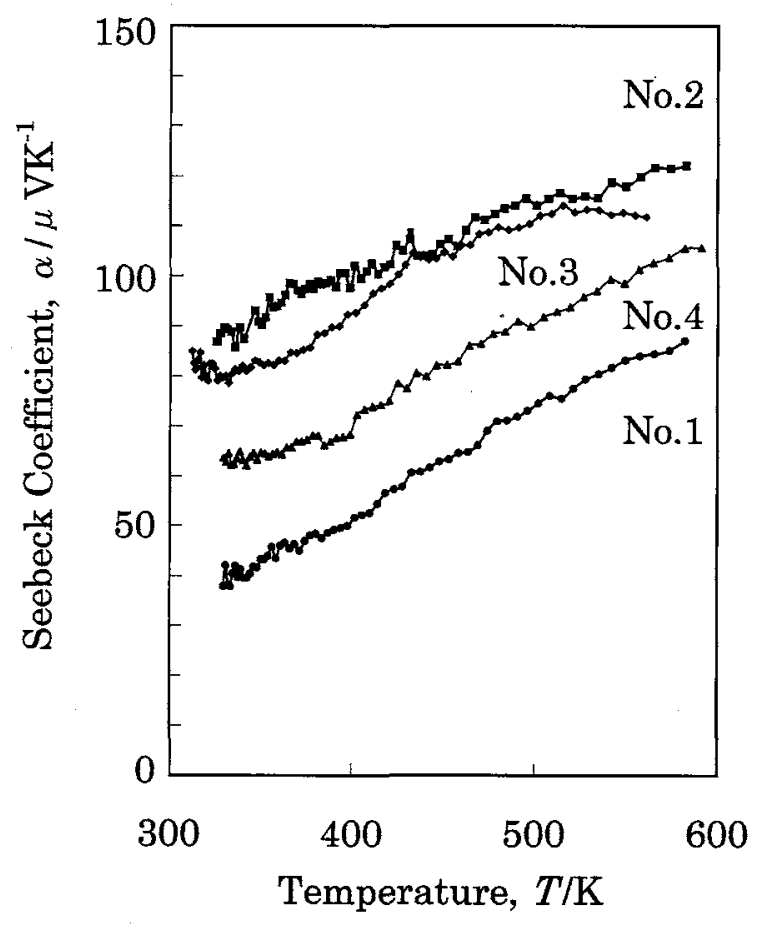

Fig. 5 Temperature dependence of Seebeck coefficients of the samples annealed at $673 \mathrm{~K}$ for $1 \mathrm{~h}$.

(2) $\mathrm{CoSb}_{3}$ 薄膜の粒径, 電気伝導度, ゼーベック係数の 值は膜組成に依存する傾向を示した。

(3) $\mathrm{CoSb}_{3}$ 薄膜は $\mathrm{p}$ 型半導体的特性を持ら, 室温での直 流后導度は $2 \times 10^{4} / \mathrm{\Omega m}, 573 \mathrm{~K}$ でのぜ一べック係数は 120 $\mu \mathrm{V} / \mathrm{K}$ 程度の值を示した。

本研究の一部は文部省科学研究費補助金基盤研究 $(\mathrm{B})$ の援 助を受けて行われたことを付記し，合わせて感謝の意を表し ます。

\section{文献}

1) C. N. Liao, C. Chen and K. N. Tu: J. Appl. Phys., 86(1999), 3204-3208.

2) Il-H. Kim and D-H. Lee: J. Mater. Res., 12(1997), 423-429.

3) T. Ohta: Materia Japan, 35(1996), 956-960 (in Japanese).

4) D. Mandrus, A. Migliori, T. W. Darling, M. F. Hundley, E. J. Peterson and I. D. Thompson: Phys. Rev., B52 (1995), 49264931.

5) E. Arushanov, K. Fess, Ch. Kloc and E. Bucher: Phys. Rev., B56 (1997), 1911-1917.

6) B. C. Sales, D. Mandrus, B. C. Chakoumakov, V. Keppens and J. D. Thompson: Phys. Rev., B56(1997), 15081-15089.

7) H. Anno, K. Hatada, H. Shimizu and K. Matsubara: J. Appl. Phys., 83 (1998), 5270-5276.

8) S. Katsuyama, Y. Shichijo, M. Ito, K. Majima and H. Nagai: J. Appl. Phys., 84(1998), 6708-6712.

9) H. Anno, K. Matsubara, Y. Notohara, T. Sakakibara, K. Kishimoto and $\mathrm{T}$. Koyanagi: International Conference on Thermoelectrics, (1996), 435-439.

10) H-M. Christen, D. G. Mandrus, D. P. Norton, L. A. Boatner and B. C. Sales: Mat. Res. Soc. Symp. Proc., Vol. 478(1997), $217-222$.

11) N. Hayahi, K. Morii, T. Matsui and Y. Nakayama: Mater. Sci. and Eng., B10 (1991), 209-215.

12) M. D. Hornbostel, H. Sellinschegg and D. C. Johnson: Mat. Res. Soc. Symp. Proc., Vol. 478 (1997), 211-216.

13) I. O. Sofo and G. D. Mahan: Phys. Rev., B58(1998), 1562015623.

14) D. J. Singh and W. E. Pickett: Phys. Rev., B50(1994), 1123511238. 